\title{
Adhesive strength in a high voltage mica insulation system
}

\author{
Tatiana Shikova \\ Peter the Great St. Petersburg Polytechnic University, St. Petersburg, Russian Federation
}

\begin{abstract}
The problem of maintaining a monolithic high-voltage mica insulation made by the Resin Rich technology for windings of electrical machines and conductors is considered. The violation of solidity like delaminations and peeling off from conductor can happen both during the process of manufacturing and during exploitation of constructions. The possibility of breaking the solidity is directly related to the magnitude of adhesion strength. Design and manufacturing technology of samples in laboratory and industrial conditions to determine the adhesion strength were developed. Adhesive strength is determined by the method of shear and tensile test method between insulation layers and in system of metal- mica insulation.The created method for the manufacture of samples made it possible to test samples with various designs of adhesive contact, materials of adhesive contact and technological parameters of the pressing process. The adhesion strength depends on the parameters of the thermal pressing process and the degree of curing of the binder in the initial resin rich tape. Adhesive contact of mica insulation to metal through fiberglass is more durable than through film
\end{abstract}

\section{Introduction}

High-voltage insulation systems of electric machines and some conductors consist of tape glass-mica paper materials (dry or resin rich). The structure of such insulation is layered composite systems consisting of mica paper, fiberglass and a binder based on epoxy resins. The improvement of such insulation systems is carried out by introducing promising new materials and optimizing the technology of their manufacture [1 - 4].

In the manufacture of insulation and during operation, defects in the form of peeling off from conductor, delamination or places of weak adhesion of the layers can occur and develop. The reason for the appearance of such defects is due to the existence of mechanical stresses proportional to the difference in the coefficients of thermal expansion of the elements of the insulation system. They must exceed the adhesion strength of the insulation layers to each other and insulation with the conductor [5 - 7]. Therefore, for layered composite materials it is necessary to ensure high cementation of the insulation layers, both between themselves and with the conductor. Cementation of layers is necessary not only to ensure the mechanical characteristics of the insulation system [8], but also can largely determine the long-term electrical strength of a layered insulation system [9 - 14]. In layered composite high-voltage insulation systems, the main stage in the development of breakdown is the discharge along the layers (interlayer) discharge [13 - 17]. The authors of classify interlayer discharges as "treeing", which grows along the interface between the mica and the binder, between the binder and fiberglass, passing from layer to layer at the points of overlap of the tapes.

Thus, to exclude the development of treeing it is necessary to reduce areas with a high binder content, increase the content of mica, increase the number of layers and improve the quality of tape application. All authors mention the need to increase the adhesion strength between the layers, which is determined by the adhesive strength (the force required to break the connection) [12, 15 - 17]. But the values of adhesive strength, their relationship with manufacturing technology and operational impacts and possible methods for its determination are not indicated. Determination of adhesive strength can be an express method for the comparative evaluation of different materials, technological and structural options for manufacturing an insulation system before testing for long-term electric strength

In this paper, the following tasks are posed:

- the choice of design and manufacturing technology for specimens to determine the adhesion strength at different directions of application of the load;

- study of the influence of technological factors, the design of the adhesive contact, the direction of application of the load on the value of adhesive strength.

\footnotetext{
*Corresponding author: t $\underline{\text { shikova@mail.ru }}$
} 


\section{Methods}

The object of study is a mica-containing insulation system made using resin rich (RR) technology. The manufacturing technology of the samples consisted of assembly and thermal pressing.

To determine the shear strength between the insulation layers, samples of the "single-lap joint" type were used (Figure 1) [18 - 20]. To eliminate the curvature of the samples during thermal pressing, elements (3) are added to the structure. The main elements of the samples, creating an adhesive contact, and elements 3 consist of 5 layers of tape containing mica paper, fiberglass and epoxynovolac binder. Such a number of tape layers provide the necessary mechanical strength of the samples in zone 2 and the destruction of the samples during testing only in the area of adhesive contact (1). Layers of tape in all areas were connected with mica paper to fiberglass. This corresponds to the arrangement of layers in a real insulation system.

Samples of this design (Figure 1) were thermally pressed in a special mold with electric heating (Figure 2). Using the Thermodat instrument, various temperature - time regimes were modeled. The required pressure level was provided by a hydraulic press.

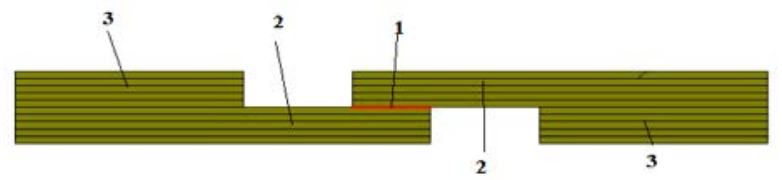

Fig.1. Design of specimens for determining shear strength between insulation layers

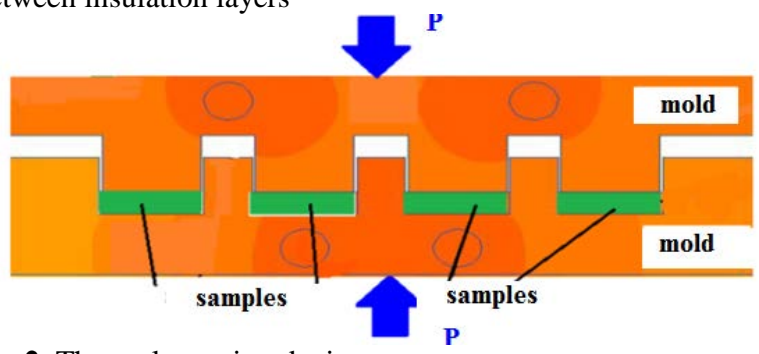

Fig.2. Thermal pressing device

In general the process of thermal pressing of the insulation of the stator windings of high-voltage generators and conductors based on resin rich tapes, consists of several stages (Figure 3): 1 - pre-heating the insulation, 2 - pressing, 3 - curing the insulation, 4 cooling. The parameters of the mode are selected based on the study of the kinetics of curing of the thermosetting binder. At stage 1, the temperature-time regime (temperature $-\mathrm{T} 1$ and duration $-\mathrm{t}$ ) provides the necessary mobility of the binder. Premature curing of the binder at the end of this stage complicates the distribution of the binder over the volume of insulation in stage 2 and leads to the appearance of pores inside the insulation and poor adhesion of the layers. A similar change is possible with insufficient mobility of the binder in the source material. When pressing the insulation with high pressure $(\mathrm{P})$, the binder is redistributed, it fills the air layers, and the insulation layers are compressed to the required size. The result of this stage (insulation thickness, amount of binder, void content in the insulation, adhesion between layers) depends on the parameters of stage 1. Subsequent curing (stage 3) of the insulation at elevated temperature completes the formation of all insulation characteristics. The temperature and curing time determine the degree of curing of the binder and set the level of mechanical and electrical characteristics of composite materials at operating temperatures.

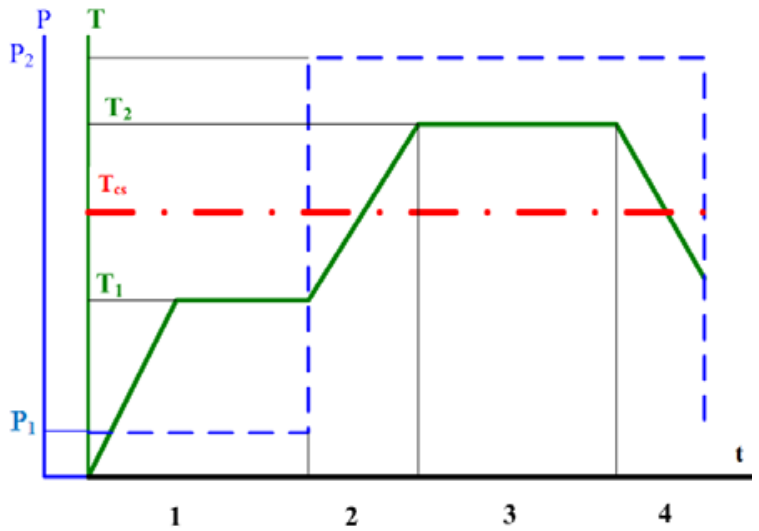

Fig.3. Schematic diagram of the thermal pressing

Thermal pressing device allows you to change all process parameters. The parameters of the basic mode of thermal pressing are selected by studying the kinetics of curing the binder in the tape. It has been previously shown that the curing start temperature (TCS) is $125^{\circ} \mathrm{C}$. The parameters of the curing stage - pressure $1 \mathrm{MPa}$, temperature $160{ }^{\circ} \mathrm{C}$ and a duration of 5 hours - are used in the industrial method of manufacturing insulation. The influence of pressure change, variation of the parameters of the preheating mode and curing temperature on the adhesive strength is determined. The modes are shown in table 1 .

\begin{tabular}{|c|c|c|c|c|c|}
\hline \multirow{2}{*}{$\begin{array}{c}\text { № } \\
\text { option }\end{array}$} & \multicolumn{2}{|c|}{$\begin{array}{l}\text { Preheating } \\
\text { parameters }\end{array}$} & \multicolumn{2}{|c|}{$\begin{array}{c}\text { Curing } \\
\text { parameters }\end{array}$} & \multirow{2}{*}{$\begin{array}{c}\mathbf{P}_{2}, \\
\mathbf{M P a}\end{array}$} \\
\hline & $\mathrm{T}_{1},{ }^{0} \mathrm{C}$ & $t_{1}, \min$ & $\mathrm{T}_{2},{ }^{\circ} \mathrm{C}$ & $t_{2}, h$ & \\
\hline 1 & 110 & 20 & 160 & 5 & 1.0 \\
\hline 2 & 140 & 5 & 160 & 5 & 1.0 \\
\hline 3 & 140 & 30 & 160 & 5 & 1.0 \\
\hline 4 & 110 & 20 & 160 & 5 & 0.5 \\
\hline 5 & 110 & 20 & 160 & 5 & 0.1 \\
\hline 6 & 110 & 20 & 140 & 5 & 1.0 \\
\hline 7 & 110 & 20 & 180 & 5 & 1.0 \\
\hline
\end{tabular}

To determine the adhesive shear strength between the metal and the insulation, a double-strap joint design was chosen based on a number of preliminary experiments (Figure 4) [18-20]. The mica tape consisted of mica paper, fiberglass, an epoxy resin binder and a polyethylene terephthalate (PET) film. The pressing of the samples was carried out according to the basic mode 1 using a thermal press device. Several options for the design of adhesive contact that can be used in a real system are investigated:

A1. The contact between the insulation and the metal was through a film;

A2. The contact between the insulation and the metal was made through fiberglass; 
A3. An additional layer was applied to the metal - a hot curing compound to increase adhesion, contact between the insulation and the metal was through a film;

A4. An additional layer was applied to the metal - a hot curing compound to increase adhesion; contact between the insulation and the metal was made through fiberglass.

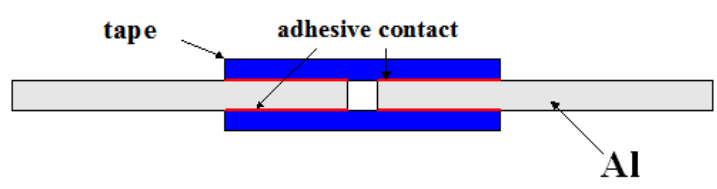

Fig.4. Design of samples for determining the shear strength between metal and insulation

To determine the adhesion strength using tensile test methods (бa) [18 - 20], samples were made of two aluminum profiles and mica-containing thermoset insulation (Figure 5). One of the profiles was covered with two layers of tape with overlapping $1 / 2$ of the width of the tape, the second aluminum profile is laid on top. The sample was placed in an autoclave for hydrostatic pressing.

The following adhesion contact design options were investigated:

B1. The contact between the insulation and the metal was through a film;

B2. The contact between the insulation and the metal was made through fiberglass;

B3 Contact between insulation layers.

In all cases, the adhesive strength is determined by the force required to break the adhesive contact (F), with a known area of adhesive contact [18]. The adhesion strength was determined by tensile testing of the samples on a universal Instron-1122 installation (obtaining tensile diagrams). Statistical data processing was carried out using the normal distribution law.

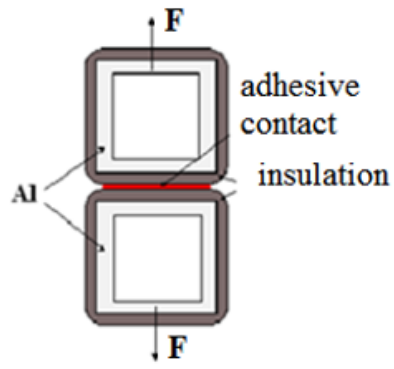

B3

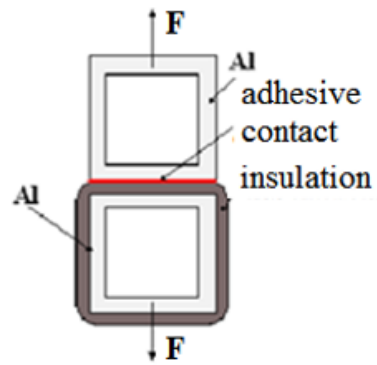

$\mathrm{B} 2, \mathrm{~B} 1$
Fig.5. The design of the sample to determine the tensile strength

\section{Results and Discussion}

It is known that the curing process of a thermosetting binder begins at a temperature of TCS $=125-130{ }^{\circ} \mathrm{C}$. Therefore, the temperature of the preheating stage - T1 should be below this value. To assess the effect of precuring at stage 1 , different modes of pre-heating samples were studied - 1 (T1 < TCS.), 2 and 3 (T1> TCS.) were studied. The test results of the samples (Figure 6) show that preliminary curing of the binder before applying pressure significantly reduces the adhesive strength. Thus, an increase in the preheating temperature to $140^{\circ}$ C leads to a decrease in strength by more than $20 \%$, and an increase in exposure time at this temperature up to 30 min - three times.

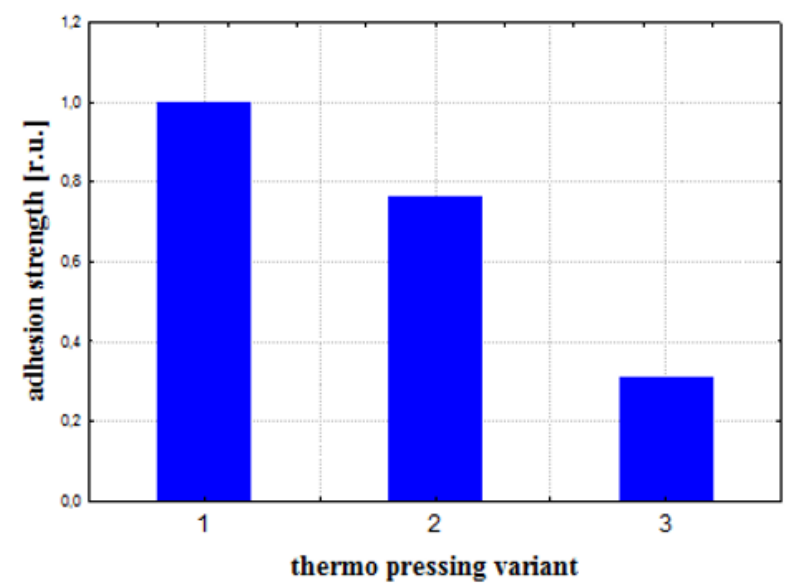

Fig.6. Effect of preheating parameters on adhesive strength

Similar results were obtained in the manufacture of samples from a tape with a different degree of curing of the binder (Figure 7). A different degree of curing was obtained by holding the tape at $\mathrm{T}=135^{\circ} \mathrm{C}>\mathrm{TCS}$ for a certain time [21]. A 50\% reduction in cure reduces adhesive strength by $20 \%$.

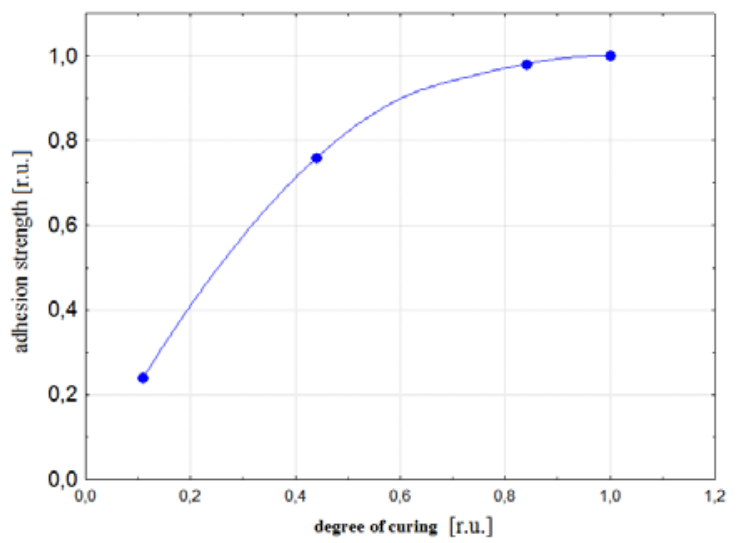

Fig.7. The effect of the degree of binder curing on the adhesive strength

The influence of the curing temperature $\left(T_{2}\right)$ on the adhesive strength of the tapes was studied on samples of options $1,6,7$. An increase in the curing temperature from $140^{\circ} \mathrm{C}$ to $180^{\circ} \mathrm{C}$ increases the adhesive strength by $20 \%$ for the same curing time. This corresponds to the known results of the curing rate changing with increasing temperature according to the Arrhenius law. But the difference between the temperature of 160 and $180^{\circ} \mathrm{C}$ is small (Figure 8). 


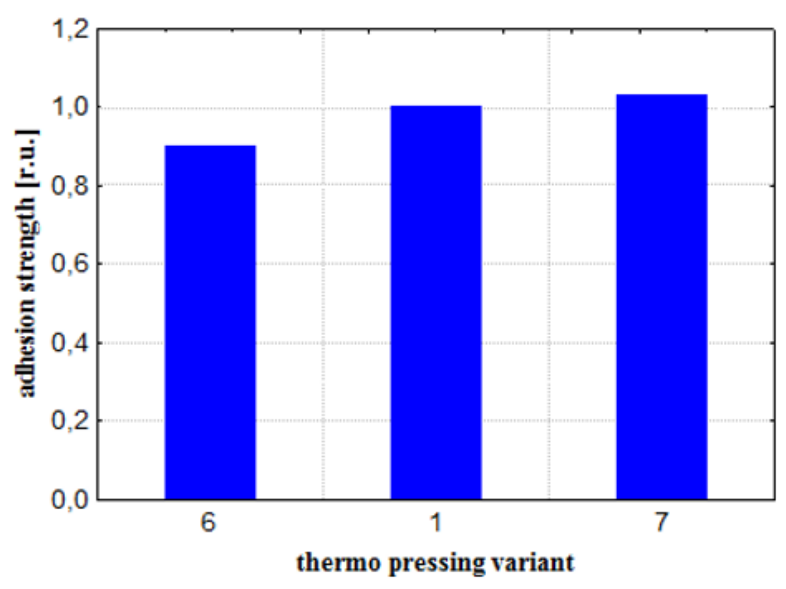

Fig.8. Effect of cure temperature on adhesive strength

The effect of pressure on the adhesive strength of the joint was carried out at three pressure levels - options 1 , 4 and 5. It can be seen from the data in Figure 9 that a pressure of $0.5 \mathrm{MPa}$ is already sufficient to create a strong adhesive bond. However, in this case, there is a significant variation in strength values (Kvar. $=24 \%$ ) and at this pressure it is impossible to guarantee the quality of insulation. Therefore, for further tests, a pressure of $1 \mathrm{MPa}$ was chosen

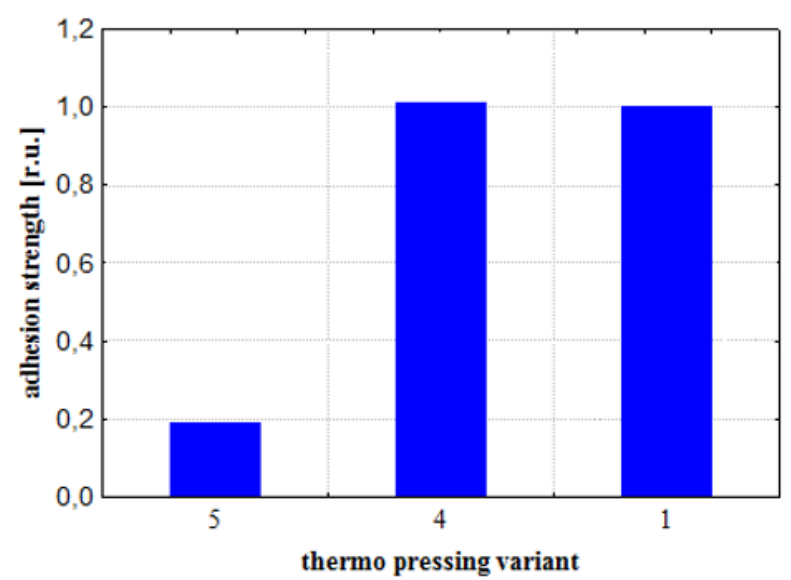

Fig.9. The effect of pressure on adhesive strength

Thus, deviations of the parameters of the thermal pressing mode from the optimum significantly increase the risk of cavities in the finished insulation structure. According to the value of adhesive strength, the parameters of option 1 are optimal.

The results of determining the adhesive strength by the shear method in the insulation - metal system (Figure 10) show that the adhesive contact through the film has minimal adhesive strength due to the absence of an adhesive layer. This is clearly visible in the pictures under the microscope (Figure 11).Changing the design of the contact to option 2 (the presence of fiberglass) increases the adhesive strength by more than an order of magnitude. Moreover, on the contact surface after rupture, there are traces of fiberglass and binder (Figure 11). The presence of a hot cure compound as an adhesive layer significantly increases the adhesive strength (A3 and A4). But the adhesive strength through fiberglass is
1.5 times higher than through film. Thus, the need for adhesive contact through fiberglass is shown.

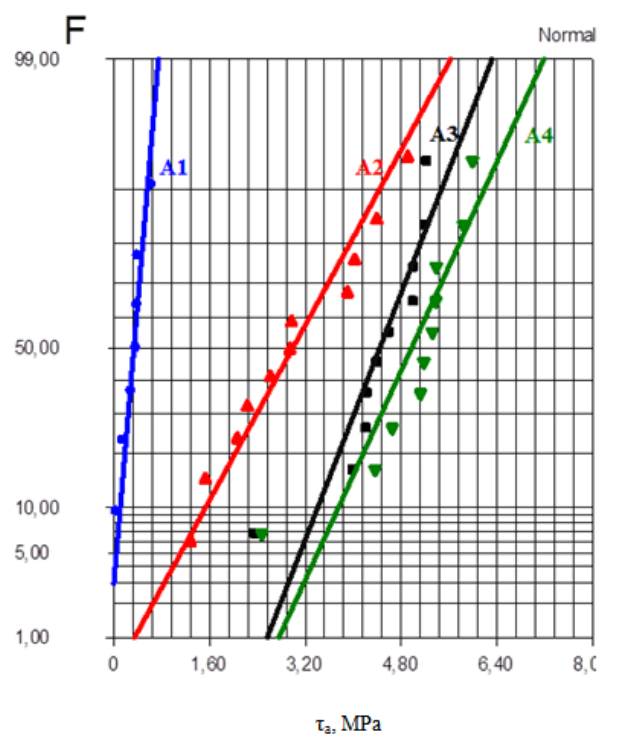

Fig.10. Effect of adhesive contact design on adhesive shear strength

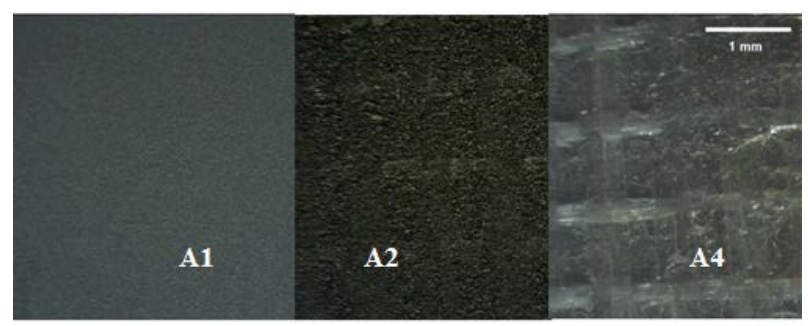

Fig.11. Photos of different adhesion contact options

Adhesion strength in the other direction of application of the load - tensile strength - is an order of magnitude lower than shear strength (Figure 12). In this case, the adhesive strength upon contact through fiberglass is also much higher than through film (B1, B2). In determining the adhesion shear strength, it was assumed that the low values of adhesive strength are due to the lack of a binder in the adhesive layer. These samples fully reproduced the manufacturing design and manufacturing process. But the conclusion about the preferred application of the tape by fiberglass to aluminum does not change. Adhesive tensile strength between insulation layers (interlayer strength) is much higher than contact strength through film. Therefore, in a real design, the weakest zone is the contact of the metal with the insulation 


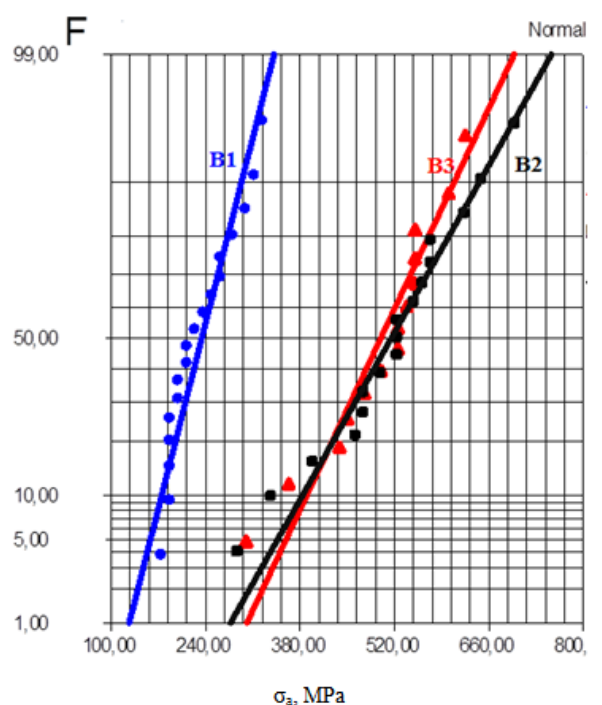

Fig.12. The influence of the design of adhesive contact on the tensile strength

\section{Conclusions}

1. The design and manufacturing technology of specimens for determining the adhesive shear strength between the layers of insulation and insulation to the metal were refined. A design and manufacturing technology (close to the production process) of samples was developed to determine the adhesion tensile strength of mica insulation.

2. The adhesive strength is largely determined by the parameters of the thermal pressing process, the degree of curing of the binder in the initial impregnated material and decreases when these parameters deviate from the optimum.

3. The adhesive strength of mica insulation to metal is determined by the design of the adhesive contact. Contact through fiberglass is significantly more durable than through film.

4. Adhesion shear strength of mica-containing insulation is significantly higher than tensile strength.

5. It is necessary to continue work to determine the adhesion strength of other technological and structural variants of the mica insulation system.

\section{References}

1.R. Bartnikas and R. Morin, IEEE Trans. Energy Convers. 19, 702 (2004)

2. R. Vogelsang, B. Fruth, T. Farr, and K. Fröhlich, Eur. Trans. Electr. Power 15, 271 (2005)

3.G. C. Stone, E. A. Boulter, I. Culbert, and H. Dhirani, Electr. Insul. Mag. IEEE 20, 65 (2004)

4.P. Gröpper, T. Hildinger, F. Pohlmann, and J. Weidner, in (2012)

5. A. Futakawa, S. Yamasaki, A. Murakaami, and

T. Kawakami, IEEE Trans. Electr. Insul. EI-18, 143

6.T. Hakamada, Y. Kashiwamura, and S. Amagi,

IEEE Trans. Electr. Insul. EI-18, 449 (1983)

7. V. Bolotin, Mech. Compos. Mater. 37, 367 (2001)
8.J. W. Wood, in IEE Colloq. Mech. Influ. Electr. Insul. Perform, 2/1-2/4 (1995)

9. S. Grzybowski, C. D. Taylor, and S. R. Chalise, 321-325 (2008)

10. K. Kimura and Y. Kaneda, IEEE Trans. Dielectr. Electr. Insul. 2, 426 (1995)

11. G. Stone, I. Culbert, E. Boulter, and H. Dhirani, 171-234 (2014)

12. T. Tanaka, IEEE Trans. Dielectr. Electr. Insul. 9, 704 (2002)

13. P. H. F. Morshuis, IEEE Trans. Dielectr. Electr. Insul. 12, 905 (2005)

14. 14. N. Shimizu and C. Laurent, Dielectr. Electr. Insul. IEEE Trans. 5, 651 (1998)

15. R. Vogelsang, R. Brutsch, T. Farr, and K. Frohlich, in (2002), 946-950

16. R. Vogelsang, T. Weiers, K. Frohlich, and R.

Brutsh, Electr. Insul. Mag. IEEE 22, 5 (2006)

17. R. Bruetsch, in (2008), 162-165

18. Y. Tarnopol'skii and V. Kulakov, Mech. Compos. Mater. 37, 431 (2001)

19. B. Duncan and L. Crocker, (2001)

20. W. Broughton, (1999)

21. E. Dümichen, U. Braun, and H. Sturm, in 